PREPARED FOR THE U.S. DEPARTMENT OF ENERGY, UNDER CONTRACT DE-AC02-76CH03073

PPPL-3725

PPPL-3725

UC-70

Impact of the Wall Conditioning Program

on Plasma Performance in NSTX

by

H.W. Kugel, V. Soukhanovskii, M. Bell, W. Blanchard,

D. Gates, B. LeBlanc, R. Maingi, D. Mueller, H.K. Na,

S. Paul, C.H. Skinner, D. Stutman, and W.R. Wampler

July 2002

NM|

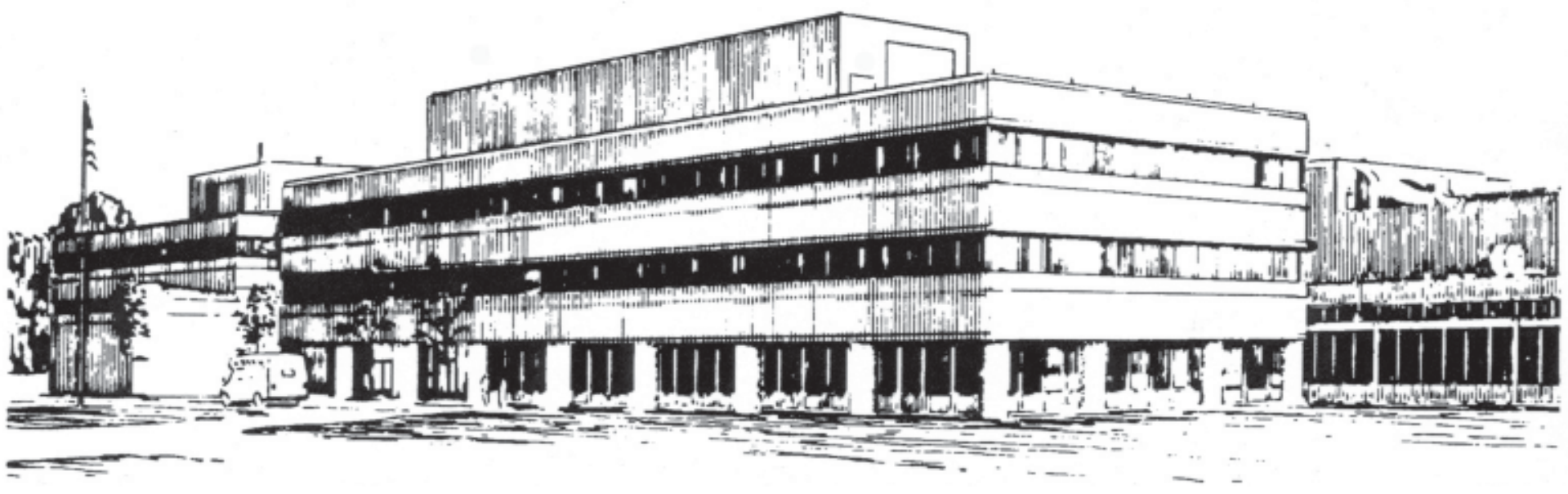

PRINCETON PLASMA PHYSICS LABORATORY PRINCETON UNIVERSITY, PRINCETON, NEW JERSEY 


\section{PPPL Reports Disclaimer}

This report was prepared as an account of work sponsored by an agency of the United States Government. Neither the United States Government nor any agency thereof, nor any of their employees, makes any warranty, express or implied, or assumes any legal liability or responsibility for the accuracy, completeness, or usefulness of any information, apparatus, product, or process disclosed, or represents that its use would not infringe privately owned rights. Reference herein to any specific commercial product, process, or service by trade name, trademark, manufacturer, or otherwise, does not necessarily constitute or imply its endorsement, recommendation, or favoring by the United States Government or any agency thereof. The views and opinions of authors expressed herein do not necessarily state or reflect those of the United States Government or any agency thereof.

\section{Availability}

This report is posted on the U.S. Department of Energy's Princeton Plasma Physics Laboratory Publications and Reports web site in Fiscal Year 2002. The home page for PPPL Reports and Publications is: http://www.pppl.gov/pub_report/

DOE and DOE Contractors can obtain copies of this report from:

U.S. Department of Energy

Office of Scientific and Technical Information

DOE Technical Information Services (DTIS)

P.O. Box 62

Oak Ridge, TN 37831

Telephone: (865) 576-8401

Fax: (865) 576-5728

Email: reports@adonis.osti.gov

This report is available to the general public from:

National Technical Information Service

U.S. Department of Commerce

5285 Port Royal Road

Springfield, VA 22161

Telephone: 1-800-553-6847 or

(703) 605-6000

Fax: (703) 321-8547

Internet: http://www.ntis.gov/ordering.htm 


\title{
Impact of the Wall Conditioning Program on Plasma Performance in NSTX
}

\author{
H. W. Kugel ${ }^{\text {a) }}$, V. Soukhanovskii ${ }^{\text {a) }}$, M. Bell ${ }^{\text {a) }}$,W. Blanchard ${ }^{\text {a) }}$, D. Gates ${ }^{\text {a) }}$, \\ B. LeBlanc ${ }^{\text {a) }}$, R. Maingi ${ }^{\text {b) }}$, D. Mueller ${ }^{\text {a) }}$, H. K. Na ${ }^{\text {c) }}$, S. Paul ${ }^{\text {a) }}$, C. H. Skinner ${ }^{\text {a) }}$, \\ D. Stutman ${ }^{\text {d) }}$,W. R. Wampler ${ }^{\text {e) }}$ \\ a) Princeton Plasma Physics Laboratory, Princeton, NJ 08543, USA. \\ b) Oak Ridge National Laboratory, Oak Ridge TN, 37831 , USA \\ c) Korea Basic Science Institute, Taejeon, Korea \\ d) Johns Hopkins University, Baltimore, MD 21218, USA \\ e) Sandia National Laboratories, Albuquerque, NM, 87123, USA
}

\begin{abstract}
High performance operating regimes have been achieved on NSTX through impurity control and wall conditioning techniques. These techniques include HeGDC-aided boronization using deuterated trimethylboron, inter-discharge HeGDC, $350{ }^{\circ} \mathrm{C}$ PFC bake-out followed by $\mathrm{D}_{2}$ and HeGDC, and experiments to test fueling discharges with either a He-trimethylboron mixture or pure trimethylboron. The impact of this impurity and density control program on recent advances in NSTX plasma performance is discussed.
\end{abstract}

Keywords: wall conditioning, impurity control, boronization, boron fueling 


\section{Introduction}

The physics principles of spherical torus (ST) geometry, characterized by strong magnetic field curvature, high beta-toroidal, and close-wall passive plate stabilizers are being evaluated by the National Spherical Torus Experiment (NSTX) [1]. Recent NSTX results include achieving a $\beta_{\mathrm{T}}$ of $\sim 31 \%$ at $\mathrm{Ip}=1.5 \mathrm{MA}$ and $\mathrm{B}_{\mathrm{T}}=0.3 \mathrm{~T}$ using $5 \mathrm{MW}$ of $80 \mathrm{keV}$ neutral beam heating [2]. In the highest stored energy discharges $(280 \mathrm{~kJ})$, the central ion temperature was $\sim 3$ $\mathrm{keV}$ and the central electron temperature $\sim 1.4 \mathrm{keV}[2]$. H-modes have been accessed routinely with confinement times up to $120 \mathrm{~ms}$ [3]. High Harmonic Fast Wave heating has achieved central electron temperatures of $\mathrm{T}_{\mathrm{e}}>3 \mathrm{keV}$ and discharges which exhibit apparent internal electron transport barriers [4]. Coaxial helicity injection, under investigation as a non-inductive current drive technique has achieved toroidal currents of $390 \mathrm{kA}$ [5]. In a relatively brief period since first plasma (1999), noteworthy results have been obtained, and new and interesting phenomena have been encountered [1]. Impurity control and wall conditioning have been essential in achieving high performance NSTX operating regimes. In 1999-2000, the initial wall conditioning of NSTX for ohmic plasma operations applied modest bake-outs of plasma facing components (center column to $309^{\circ} \mathrm{C}$, passive plate $\mathrm{PFC}$ 's to $220{ }^{\circ} \mathrm{C}$ ), and extensive glow discharge cleaning (GDC) in deuterium and helium [6]. Beginning in late 2000, the installation of $5 \mathrm{MW}$ of neutral-beam injection (NBI), $6 \mathrm{MW}$ of high harmonic fast wave (HHFW) radiofrequency heating, and high toroidal current (390 kA), Coaxial Helicity Injection (CHI) for noninductive startup has required upgrading the wall conditioning techniques to provide additional impurity and density control. These techniques include HeGDC-aided boronization using deuterated trimethylboron, inter-discharge HeGDC, $350{ }^{\circ} \mathrm{C}$ PFC bake-out followed by $\mathrm{D}_{2} \mathrm{GDC}$ and HeGDC, and experiments to test fueling of deuterium discharges with a He-trimethylboron mixture and pure trimethylboron.

\section{HeGDC/TMB Boronization}

Boronization has significantly improved plasma performance [7] and allowed routine access to H-modes [3]. A $90 \% \mathrm{He}$ and $10 \%$ deuterated trimethylboron $(\mathrm{TMB})\left[\mathrm{B}\left(\mathrm{CD}_{3}\right)_{3}\right]$ mixture was injected into a HeGDC. Separate He and He-TMB gas injectors were set for equal flow rates, to give a 95\% He and 5\% TMB application mixture. Ten g of TMB was applied 
over 160 minutes [8]. Residual Gas Analyzer (RGA) spectra indicate high oxygen impurity removal rates $\left(\mathrm{H}_{2} \mathrm{O}, \mathrm{D}_{2} \mathrm{O}, \mathrm{CO}\right)$, during the TMB boronization process due to PFC sputtering by the process constituents. Each boronization was followed by about 120 minutes of pure HeGDC to remove residual deuterium co-deposited during the process. Measurements of sample coupons exposed on a reciprocating probe on the mid-plane near a GDC anode indicated the film deposition thickness was about $70 \mathrm{~nm}$ per application with $\mathrm{B} / \mathrm{C}$ ratios of 0.37 and $\mathrm{D} /(\mathrm{B}+\mathrm{C})$ ratios of 0.63 [6]. More recent results from a toroidal array of coupons indicate about a factor of 5 variation in deposition thickness measured on the mid-plane; the thickest deposition occurred on a coupon between the injection point and a GDC anode. Reference $\mathrm{D}_{2}$ discharges before and after the first boronizations showed about a 94\% reduction in centerline oxygen luminosity, and about a 50\% decrease in carbon luminosity [7]. The loop voltage was reduced by $20-30 \%$, during the plasma current flat top, and ohmic flux consumption during current ramp-up decreased by $20 \%$, extending the duration of the plasma current flat top by about $70 \%$. The $\mathrm{D}_{2}$ density limit increased from approximately $60 \%$ of the Greenwald limit scaling to about $75 \%-80 \%$ after boronization, and the He density limit increased from $75 \%$ to $100 \%$ of the Greenwald limit scaling. Access to H-mode plasmas occurred after the 3rd boronization. The peak H-mode energy confinement exceeded $100 \mathrm{~ms}$ and the highest toroidally averaged Beta exceeded 25\% [9]. More recently, toroidally averaged values of toroidal beta have reached about $31 \%$ [2]. HeGDC/TMB has been applied on 16 separate occasions, or about every 300-400 discharges. Fiducial discharges performed between boronizations indicate that HeGDC boronization consistently reduced oxygen and carbon and improved performance. Fig. 1 shows the reduction in oxygen and carbon luminosities for boronizations 1 through 5.

\section{HeGDC Between Discharges}

HeGDC has been applied each morning for about 20-30 minutes prior to the start of operations. In addition, HeGDC applied between discharges was found to significantly enhance impurity control during NBI discharges and density control in ohmic plasmas [6]. Typical NSTX discharge repetition rates are between 7-12 minutes. Using pre-ionization filaments, HeGDC can be initiated between discharges at the subsequent operating pressure ( $4 \mathrm{mTorr}$ ) and bias voltage (400V) [8], and applied for 5 to 10 minutes depending on the experimental needs. RGA spectra measured before and after between-discharge HeGDC indicate about a net factor of $\sim 10$ 
reduction in $\mathrm{D}_{2}$ fuel gas, and $\mathrm{H}_{2} \mathrm{O}$ and $\mathrm{CO}$ that had presumably diffused to PFC surfaces by power deposition during a discharge.

\section{Bake-out to $350{ }^{\circ} \mathrm{C}$ Aided by $\mathrm{D}_{2}$ GDC and HeGDC Impurity Removal}

After the 10th boronization, a new bake-out system was used to perform a uniform bake-out of the PFC's to $350{ }^{\circ} \mathrm{C}$ with the vacuum vessel at $150{ }^{\circ} \mathrm{C}$. The inner PFCs are heated resistively by passing current through the inner inconel tube of the vacuum vessel while the outer PFCs are heated by circulating high-pressure helium through internal tubes. The nominal plasma-facing area of the vessel interior is $41 \mathrm{~m}^{2}$; about $75.6 \%\left(31 \mathrm{~m}^{3}\right)$ consists of graphite tiles and the remaining $24.4 \%$ is vessel wall (304-SS). The mass of the graphite PFC's is $1.3 \times 10^{3} \mathrm{~kg}$. During vessel bake-out, the PFC temperature is raised from room temperature to $350{ }^{\circ} \mathrm{C}$ over 1 day; the $350{ }^{\circ} \mathrm{C}$ phase proceeds for about 2-3 days, and 1 day is used to cool down to room temperature. During the entire bake-out, the vessel is pumped at the normal rate of $3.4 \times 10^{3} \mathrm{l} / \mathrm{s}$ (for $\mathrm{D}_{2}$ ). The rate of temperature rise was chosen to minimize mechanical vessel stress. At this rate of temperature rise, the vessel base pressure peaks in the range from about $5 \times 10^{-5}$ Torr to $5 \times 10^{-4}$ Torr (depending on the recent vacuum history) and is dominated by the partial pressures of mass 18 AMU (water) and to lesser extent mass 28 AMU (CO). Typically, after the maximum in base pressure is reached at $350{ }^{\circ} \mathrm{C}$, the subsequent decrease in the primary partial pressure components at constant temperature is exponential with at least 2 time constants. The water desorption, for example, decreases a factor of 2 in $4.5 \mathrm{hrs}$, which after $8 \mathrm{hrs}$ of $\mathrm{D}_{2} \mathrm{GDC}$ and $8 \mathrm{hrs}$ of HeGDC, becomes much slower, with a decrease of a factor of 2 in $35.8 \mathrm{hrs}$. The CO desorption is slower than that of water, decreasing a factor of 2 in $8 \mathrm{hrs}$, which after GDC decreases a factor of 2 in $35.8 \mathrm{hrs}$. The initial fast desorption rate of these partial pressures may be due to the liberation of lightly-adhering, near-surface gases, while the slower desorption rate, may be due to volume diffusion to the surfaces. It was found that a $350{ }^{\circ} \mathrm{C}$ bake-out by itself was insufficient to obtain the desired reductions in spectroscopic oxygen and carbon but that boronization following bake-out was essential to obtain a very strong and lasting effect on oxygen suppression (Fig.2 shows the relative intensities of $\mathrm{O}$ and $\mathrm{B}$ for discharges before and after Bake-out and subsequent boronization). In addition, a similar trend occurred in the discharged-average H/D ratio for deuterium discharges which decreased from values exceeding 0.2 for some discharges, to below 0.05 after bake-out followed by boronization, and continued 
decreasing. This behavior can be understood as due to possible insufficiently baked water sources, and to the ongoing diffusion of hydrogen containing impurities from the large PFC bulk volume to the near-surface region where fast desorption and plasma sputtering occur.

\section{Plasma Boronization: Fueling With $90 \%$ He and $10 \%$ TMB}

Previously, it was found that boron gases injected into the plasma edge of large aspectratio tokamaks re-boronizes plasma-wetted surfaces and improved plasma performance [10,11]. More recently on PISCES [12], the injection of carborane $\left(\mathrm{C}_{2} \mathrm{~B}_{10} \mathrm{H}_{12}\right)$ into the plasma edge resulted in very high boron film deposition rates on target samples (up to $30 \mathrm{~nm} / \mathrm{s}$ ). This was attributed in part to high rates of ionization and dissociation of the injected carborane, and to good transport of the products to the plasma wetted target. Motivated by these results, NSTX has performed preliminary investigations of the re-boronization of plasma eroded surfaces by direct injection of the $90 \% \mathrm{He}$ and $10 \% \mathrm{TMB}$ mixture into the edge plasma to determine its behavior in the close-wall NSTX geometry. This experiment was performed under relatively clean wall conditions ( 3 weeks after 7 th boronization). Before and after the discharge fueling sequence, 0.8 MA Lower Single Null (LSN) Ohmic fiducial discharges, 0.9 MA NBI heated LSN fiducial discharges, and 1.0 MA NBI heated Inner Wall Limited (IWL) fiducial discharges were performed. Fig. 3 (top) shows the discharge fueling sequence for the direct injection of $90 \% \mathrm{He}$ and 10\% TMB into an $800 \mathrm{kA}, \mathrm{D}_{2}$ Ohmic discharge. The fueling sequence was started with about 1 Torr-liter injected into the discharge. As the fueling reached 8 Torr-liters per discharge, about $75 \%$ of the discharge power was being radiated, and all the available inductive flux swing was used by the end of the current flat top. As the fueling reached 15.8 Torr-liters per discharge, the $800 \mathrm{kA}$ fiducial discharge was only able to reach $500 \mathrm{kA}$ with a short $75 \mathrm{~ms}$ flat top, at maximum available volt-sec consumption. This reduced performance at the highest fueling rates is attributed in part to excessive radiation and recycling by the He component in the fueling gas. In order to prevent radiative collapse of the discharge, the fueling for the subsequent 6 discharges was reduced to about 6 Torr-liters per discharge (11 discharges total). The total amount of injected TMB mixture (90\% He and 10\% TMB) was 65.9 Torr-liters. This corresponded to 17 $\mathrm{mg}$ of $\mathrm{BC}_{3}$, and a deposition of thickness of only $0.2 \mathrm{~nm}$ if spread uniformly over the $40.1 \mathrm{~m}^{2}$ PFC internal area. In PISCES (12) the injected fuel is promptly ionized and is then transported along field lines to plasma-wetted surfaces. In this case, the deposition thickness in a Lower 
Single Null NSTX diverted plasma with $1 \mathrm{~cm}$ wide wetted widths on a divertor region of area $0.15 \mathrm{~m}^{2}$, the deposition thickness would be $58 \mathrm{~nm}$ (assuming no re-sputtering), which is comparable to average thickness achieved in standard HeGDC-aided boronization. No experimental information is available at this time on the erosion coincident with the deposition. During the fueling sequence most of the vessel view-port shutters were closed to prevent possible depositions resulting in decreases in view-port transmission; the exceptions included the more distant spectroscopic view-ports. During the fueling sequence, it was found that edge $\mathrm{O}$ and C luminosities were comparable to before TMB fueling, within the limited statistics, due to the initially clean conditions (Fig.3). Core oxygen was reduced, and as was found previously in larger aspect ratio tokamaks [10,11]. Edge fueling with the TMB mixture did not increase core B V and C VI for the close-wall NSTX geometry (Fig.3). Plasma boronization lead to better ohmic performance. A comparison of NBI heated Center-Stack Limited (CSL) discharges found plasma boronization lead to lower radiated power and steeper outer edge profiles. A comparison of LSN, 1 MA, 1.5 MW, NBI fiducial discharges before and after fueling showed $\sim 50 \%$ decrease in central radiation. An NBI heated LSN diverted discharge following plasma boronization lead to lower radiated power and an H-mode transition not seen in the discharge before TMB fueling.

These plasma boronization results indicate that direct injection of relatively small amounts of $90 \% \mathrm{He} / 10 \%$ TMB leads to better plasma performance. No information on the duration of the improvements in performance versus discharge number, following the fueling sequence could be obtained due to the experimental schedule. However, it was found during the subsequent NBI LSN H-mode experiments that the preceding plasma boronization obviously facilitated the transitioning of discharges into the $\mathrm{H}$-mode. The results from fueling with $90 \% \mathrm{He}$ and $10 \% \mathrm{TMB}$ indicated that the presence of helium in the TMB fuel mixture injected into deuterium discharges at the highest fueling rates reduced performance, and that this was due in part to excessive radiation and recycling by the He component. Hence, this would make this fuel inconvenient to use for near-continual injection into every deuterium discharge for maintaining plasma performance. This motivated experiments using pure TMB fueling to optimize reboronization and to investigate the effects of cladding the plasma edge in a low- $Z$ mantle 


\section{Plasma Boronization: Fueling With 100\%TMB}

An initial fueling experiment was performed by injecting $100 \%$ pure TMB into deuterium discharges. About $185 \mathrm{mg}$ of boron compound was deposited in the fueling sequence shown in Fig. 4 (top). Initially, each TMB fueling discharge was followed by an NBI fiducal discharge to allow characterization of incremental changes. Later in the TMB fueling sequence, NBI fiducial discharges were taken only after sequences of 4 to 10 fueling discharges. It was found that the fraction of radiated power to total power during NBI fiducial discharges before and after the fueling sequence remained about the same at about 0.11 . This is suggestive of the possible screening of the $\mathrm{B}$ and $\mathrm{C}$ components of TMB molecules discussed previously [10]. In addition, it was found that although the oxygen and carbon impurity levels decreased initially, and that the plasma performance continued to improve during the fueling sequences, these $\mathrm{O}$ and $\mathrm{C}$ luminosities remained relatively high. Fig. 4 shows that the O VIII/C VI luminousity ratio decreased relative to the NBI fiducial discharges by about a factor of 2 . This may be due in part to a decrease in temperature during the TMB fueling discharge. Analysis of filtered USXR spectra indicates that about a $30 \%$ reduction in central $\mathrm{T}_{\mathrm{e}}$ occurred. Additional analysis of this and the influence of possible transport effects is awaiting future measurements of impurity profiles. Although starting from cleaner wall conditions would have been desirable, it is noteworthy that there was sufficient improvement in edge conditions that one of the highest central electron temperatures $\mathrm{T}_{\mathrm{e}}(0) \sim 1.6 \mathrm{keV}$ in NBI heated discharges to date was observed in a fiducial discharge following a TMB fueling sequence (Fig. 5).

\section{Conclusions}

It has been found that high temperature bake-out $\left(350^{\circ} \mathrm{C}\right)$ is needed to expedite the removal of water and $\mathrm{CO}$ absorbed on the plasma facing surfaces and near-surface regions of the graphite PFC's. Daily HeGDC and inter-discharge HeGDC are required for impurity and density control during high power operations. Experiments exploring the potential for real-time maintenance of boron films and the effects of cladding the plasma in a particular low-Z mantles have shown interesting promise and will be continued. The wall conditioning effort described in this work has facilitated a broad range of encouraging advances. 


\section{Acknowledgements}

This work supported by US DOE Contracts DE-AC02-76CH03073, DE-AC05-00OR22725, and DE-AC04-94AL85000, and Grant DE-FG02-99ER54523.

\section{References}

1. M. Ono, et al., Nucl. Fusion 40 (3Y) (2000) 557.

2. D. Gates, et al.,Proc. of the 29th EPS Conference on plasma Physics and Controlled Fusion,17-21 June 2002, Montreux, Switzerland.

3. R. Maingi, et al., Phys. Rev. Lett., 88 (3), (2002) 035003.

4. J. Synakowski, Plasma Phys. Control. Fusion, 44 (2002) A165.

5. R. Raman, et al., Proc. 18th IAEA Fusion Energy Conference, IAEA-CN-77/EX8/5, Sorrento, Italy, October 4-10, 2000; also Nuclear Fusion 41 (2001) 1081

6. H. W. Kugel, et al, J. Nuc. Mater. 290-293 (2001)1185.

7. C. H. Skinner, et al. Nucl. Fusion 42, (2002) 329.

8. W.R. Blanchard, et al, Proc. of the 19th IEEE/NPSS Symposium On Fusion Engineering Jan 22-25, 2002, Atlantic City, NJ

9. S.A. Sabbagh, et al., Phys. Plasmas Vol. 9, (2002) 2085.

10. H.G. Esser, et al., Nucl. Fusion, 32 (1992) 278.

11. C. Boucher, et al., J. Nucl. Mater., 196-198 (1992) 587.

12. O. Buzhinskij, et al., Paper P2-13, Proc. of the 15th International Conference on Plasma Surface Interactions in Controlled Fusion Devices, Gifu, Japan, May 27-31, 2002. 


\section{Figure Captions}

Figure 1. Oxygen and carbon luminosities for boronizations 1 through 5. GDC boronization with deuterated TMB consistently reduced oxygen and carbon. The results are must comparable for a given boronization because some change in the fiducial discharges occurred between boronizations.

Figure 2. Relative intensities of O VIII/C VI (top) and B V /C V (bottom) for discharges before and after Bake-out and subsequent boronization.

Figure 3. The 90\% He-10\% TMB fueling discharge sequence (top), and oxygen, carbon, and boron luminosities. The clean initial edge conditions were only marginally improved. Edge fueling with TMB did not increase B V and C VI.

Figure 4. The TMB (100\%) fueling discharge sequence (top), and the oxygen, carbon, and boron relative intensities.

Figure 5. Comparison of electron temperature, and pressure profiles for one of the highest central electron temperatures, $\mathrm{T}_{\mathrm{e}}(0) \sim 1.6 \mathrm{keV}$ achieved in NBI heated discharges observed in a fiducial discharge following a TMB fueling sequence (solid), and a fiducial discharge of the same density before TMB fueling started (dashed). 

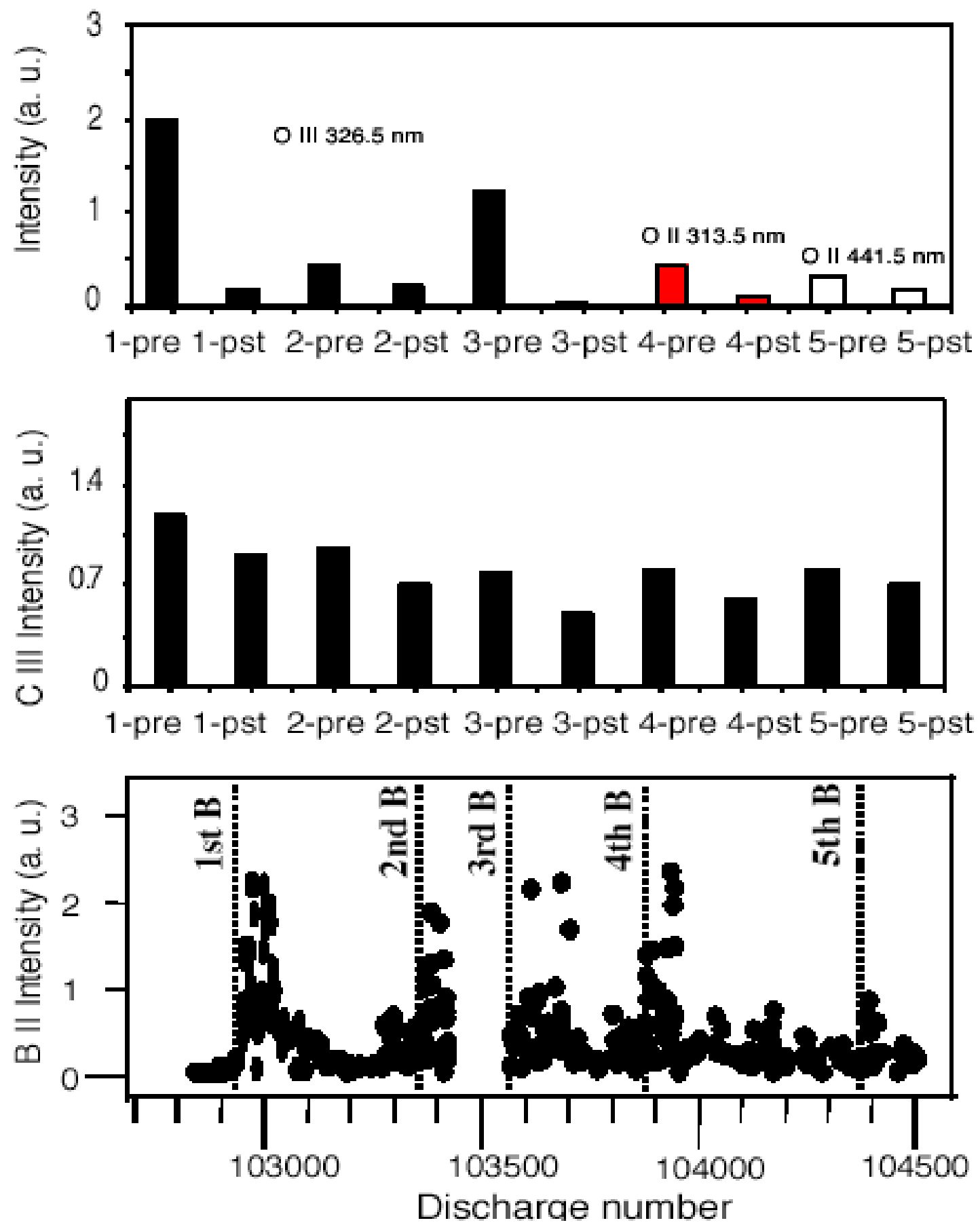

Fig.1. Oxygen and carbon luminosities for boronizations 1 through 5. GDC boronization with deuterated TMB consistently reduced oxygen and carbon. The results are must comparable for a given boronization because some change in the fiducial discharges occurred between boronizations. 


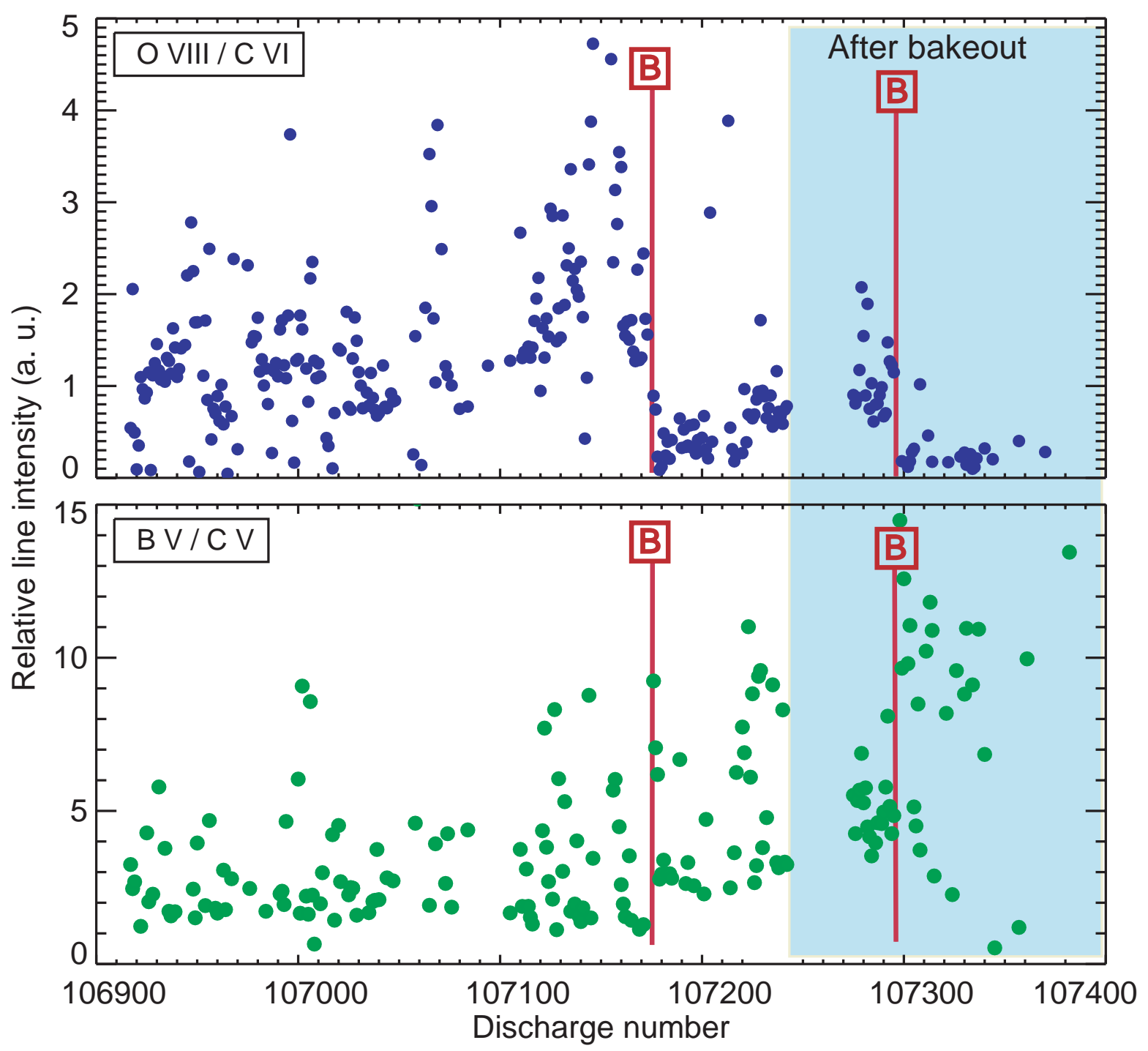

Fig.2. Relative intensities of O VIII/C VI (top) and B V /C V (bottom) for discharges before and after the Bake-out and subsequent boronization. 

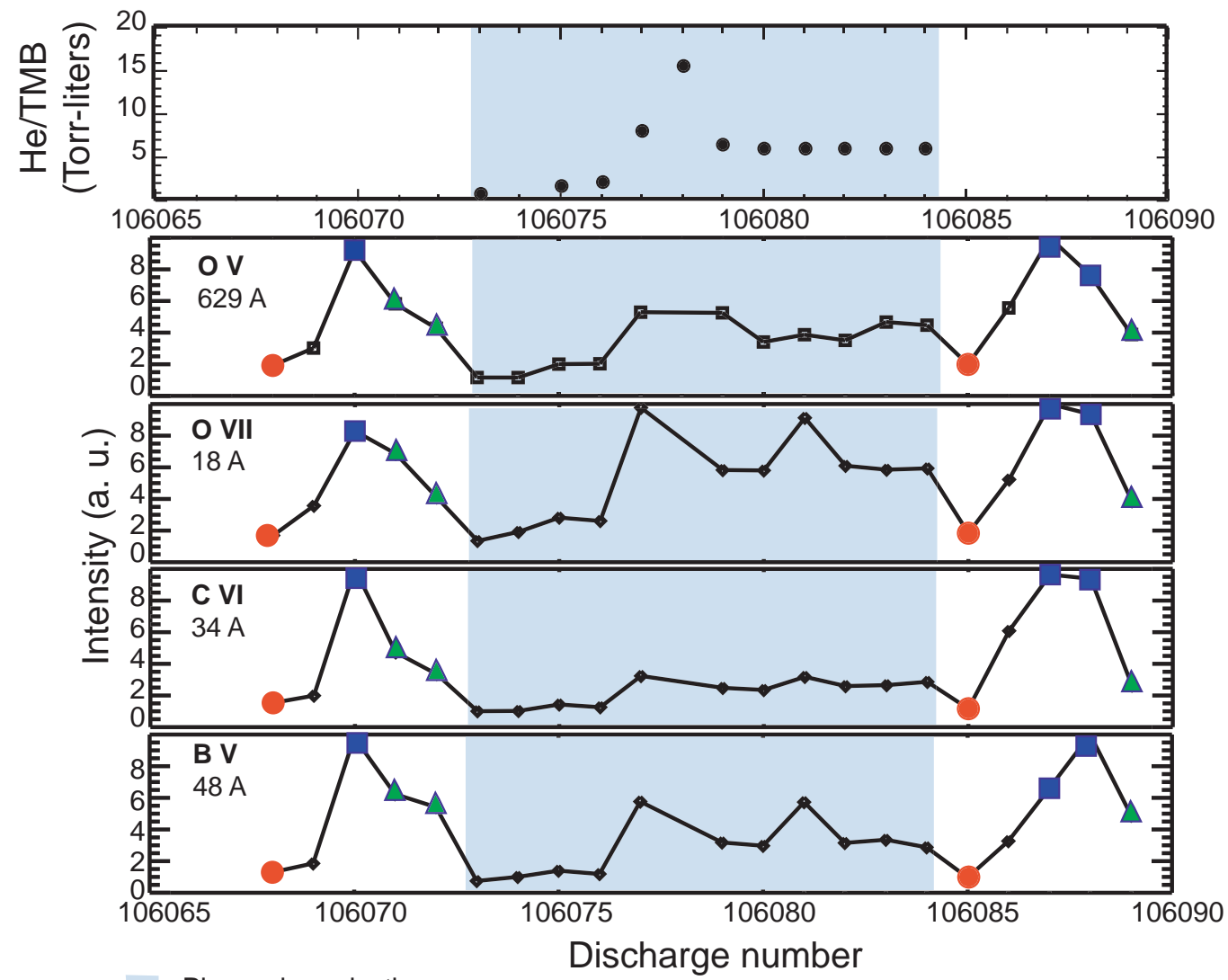

Plasma boronization

0.8 MA LSN ohmic fiducial discharge

$\triangle \quad 0.9 \mathrm{MANBI}$ heated LSN fiducial

- 1.0 MA NBI heated IWL fiducial discharge

Fig.3. The 90\% He-10\% TMB fueling discharge sequence (top), and oxygen, carbon, and boron luminosities. The clean initial edge conditions were only marginally improved. Edge fueling with TMB did not increase B V and C VI. 

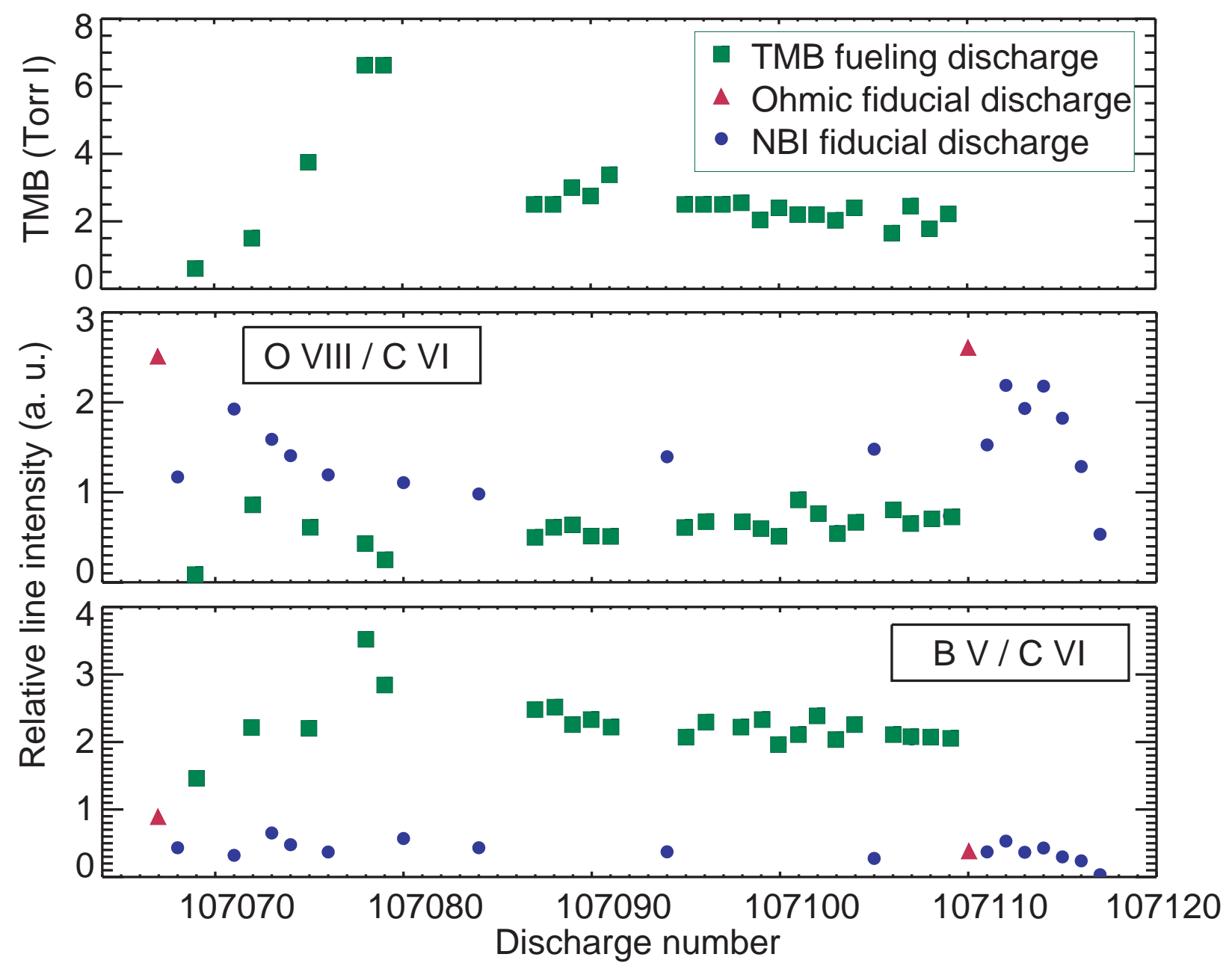

Fig.4 The TMB (100\%) fueling discharge sequence (top), and the oxygen, carbon, and boron relative intensities. 

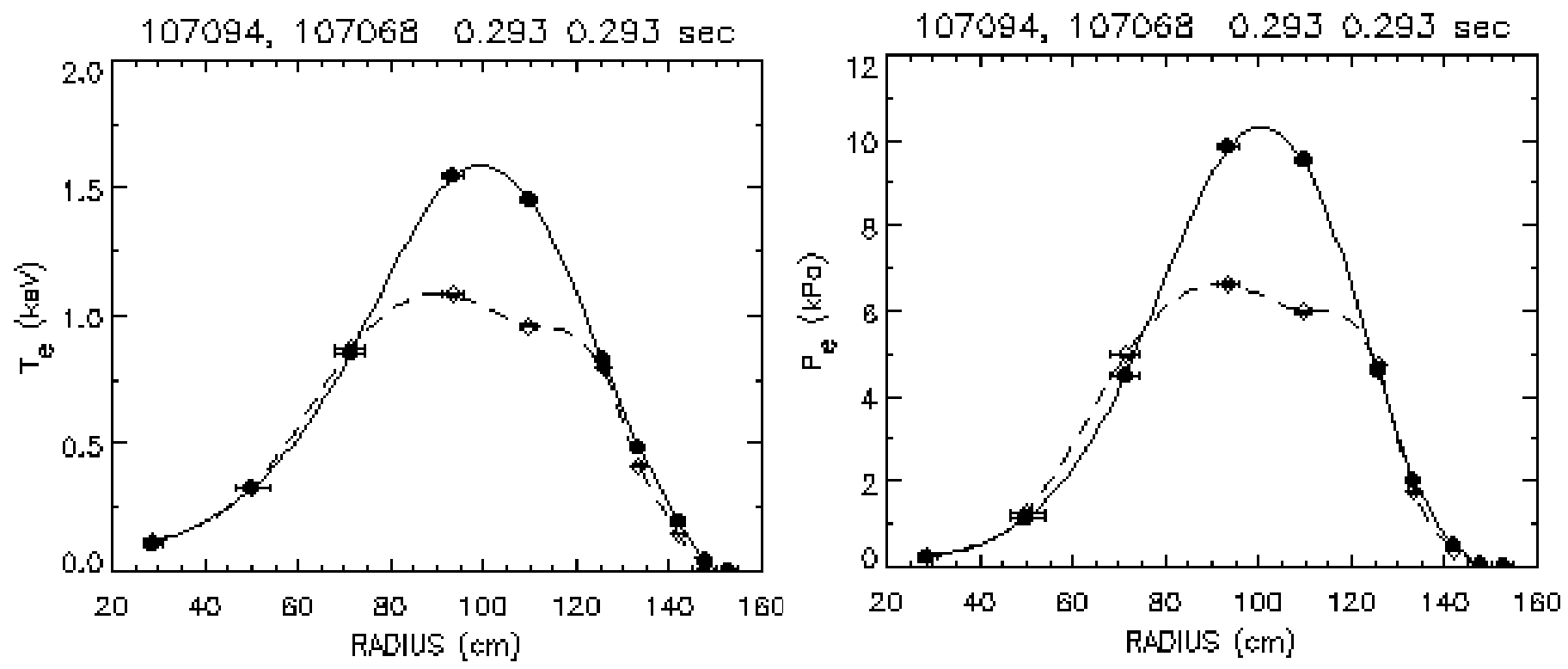

Fig.5. Comparison of electron temperature, and pressure profiles for one of the highest central electron temperatures, $\mathrm{T}_{\mathrm{e}}(0) \sim 1.6 \mathrm{keV}$ achieved in NBI heated discharges observed in a fiducial discharge following a TMB fueling sequence (solid), and a fiducial discharge of the same density before TMB fueling started (dashed). 


\section{External Distribution}

Plasma Research Laboratory, Australian National University, Australia

Professor I.R. J ones, Flinders University, Australia

Professor J oão Canalle, Instituto de Fisica DEQ/IF - UERJ , Brazil

Mr. Gerson O. Ludwig, Instituto Nacional de Pesquisas, Brazil

Dr. P.H. Sakanaka, Instituto Fisica, Brazil

The Librarian, Culham Laboratory, England

Library, R61, Rutherford Appleton Laboratory, England

Mrs. S.A. Hutchinson, JET Library, England

Professor M.N. Bussac, Ecole Polytechnique, France

Librarian, Max-Planck-Institut für Plasmaphysik, Germany

J olan Moldvai, Reports Library, MTA KFKI-ATKI, Hungary

Dr. P. Kaw, Institute for Plasma Research, India

Ms. P.J . Pathak, Librarian, Insitute for Plasma Research, India

Ms. Clelia De Palo, Associazione EURATOM-ENEA, I taly

Dr. G. Grosso, Instituto di Fisica del Plasma, Italy

Librarian, Naka Fusion Research Establishment, J AERI, J apan

Library, Plasma Physics Laboratory, Kyoto University, J apan

Research Information Center, National Institute for Fusion Science, J apan

Dr. O. Mitarai, Kyushu Tokai University, J apan

Library, Academia Sinica, Institute of Plasma Physics, People's Republic of China

Shih-Tung Tsai, Institute of Physics, Chinese Academy of Sciences, People's Republic of China

Dr. S. Mirnov, TRINITI, Troitsk, Russian Federation, Russia

Dr. V.S. Strelkov, Kurchatov Institute, Russian Federation, Russia

Professor Peter Lukac, Katedra Fyziky Plazmy MFF UK, Mlynska dolina F-2, Komenskeho Univerzita, SK-842 15 Bratislava, Slovakia

Dr. G.S. Lee, Korea Basic Science Institute, South Korea

Mr. Dennis Bruggink, Fusion Library, University of Wisconsin, USA

Institute for Plasma Research, University of Maryland, USA

Librarian, Fusion Energy Division, Oak Ridge National Laboratory, USA

Librarian, Institute of Fusion Studies, University of Texas, USA

Librarian, Magnetic Fusion Program, Lawrence Livermore National Laboratory, USA

Library, General Atomics, USA

Plasma Physics Group, Fusion Energy Research Program, University of California at San Diego, USA

Plasma Physics Library, Columbia University, USA

Alkesh Punjabi, Center for Fusion Research and Training, Hampton University, USA

Dr. W.M. Stacey, Fusion Research Center, Georgia Institute of Technology, USA

Dr. J ohn Willis, U.S. Department of Energy, Office of Fusion Energy Sciences, USA

Mr. Paul H. Wright, Indianapolis, Indiana, USA 
The Princeton Plasma Physics Laboratory is operated by Princeton University under contract with the U.S. Department of Energy.

\author{
Information Services \\ Princeton Plasma Physics Laboratory \\ P.O. Box 451 \\ Princeton, NJ 08543
}

Phone: 609-243-2750

Fax: 609-243-2751

e-mail: pppl_info@pppl.gov

Internet Address: http://www.pppl.gov 